\title{
Contribution of 99M TC-HMDP Bone Scintigraphy in the Di- agnosis of Fibrous Dysplasia of Mccune Albright Syndrome in Infant: A Case Report
}

\author{
F Fokoue*, S El Mselmi and N Ismaili Alaoui \\ Nuclear Medicine Service of Teaching Hospital Hassan 2 Fez, Morocco
}

*Corresponding author: FOKOUE FABRICE, Nuclear Medicine Service of Teaching Hospital Hassan 2 Fez, Morocco

\section{Introduction}

McCune Albright syndrome is a rare congenital disorder, which is classically defined by a triad associating a Fibrotic Dysplasia (DF) most often polyostotic, "café au lait" skin pigmentation and a hyperfunctioning endocrinopathy. "Café au lait" skin pigmentations are macules which are common and mostly the first manifestation of the disease, apparent at or shortly after birth. Fibrous Dysplasia (FD), which can involve any part and combination of the craniofacial, axial, and/or appendicular skeleton, can range from an isolated, asymptomatic monostotic lesion discovered incidentally to severe disabling polyostotic disease involving practically the entire skeleton and leading to progressive scoliosis, facial deformity, and loss of mobility, vision, and/or hearing. Endocrinopathies can include any of the following: Precocious puberty, fertility, testicular abnormalities, thyroid disease, growth hormone excess, FGF23-mediated phosphate wasting and Hypercortisolism. The diagnosis is often made on bone or endocrine involvement $[1,2]$.

Here we report the case of an infant with McCune-Albright syndrome who was diagnosed with polyostotic fibrous dysplasia using $99 \mathrm{~m}$ Tc-HMDP bone scintigraphy outside the clinical presentation, although not conventionally presented by the infant. The aim of this work is to show the interest of bone scintigraphy in the diagnosis of McCune Albright syndrome.

\section{Patient and Method}

It was a 2 years and 6 months girl, with no particu- lar medical story admitted to the pediatric consultation of the teaching hospital Hassan 2 for management of a precocious puberty. According to her story the girl presented with vaginal bleeding associated with breast development at 10 months of age. The evolution was marked by the appearance of pubic hair at 13 months. The physical examination showed a weight at $14 \mathrm{~kg}(+2$, $5 \mathrm{SD})$, a size of $87 \mathrm{~cm}(+2.8 \mathrm{SD})$ a $\mathrm{PC}$ at $48 \mathrm{~cm}(+1.5 \mathrm{SD})$, a blood pressure at $0.9 / 0.5 \mathrm{~cm} \mathrm{Hg}$ (no HBP). The inspection did not reveal any skin lesion, particularly in "café au lait" skin pigmentation. Endocrine examination revealed an impairment of the gonadotropic axis (mammary development with Tanner stage 3 pigmented nipple), without affecting the other axes. Moreover, there were no clinical sign of bone involvement. The biological assessment showed an FSH level $<0.05 \mathrm{mIU} / \mathrm{mL}$, $\mathrm{LH}$ at $0.03 \mathrm{mIU} / \mathrm{mL}, 17 \mathrm{~B}$ oestradiol at $752 \mathrm{pg} / \mathrm{mL}$, the $\mathrm{LH}-\mathrm{RH}$ test was suggestive of a peripheral origin. The radiological assessment showed a bone age of 4 years and 2 months. Ultrasound and pelvic MRI revealed a significantly enlarged uterus in relation to age, measuring $56 \times$ $20 \mathrm{~mm}$ with the presence of a left ovarian cyst measuring $20 \mathrm{~mm}$. The diagnosis of McCune Albright Syndrome has been suspected in this chart. A 99mTC-HMDP bone scan was requested looking for fibrous dysplasia.

\section{Results}

Static images of the skeleton $2 \mathrm{~h}$ after intravenous injection of a dose of $407 \mathrm{MBq}(11 \mathrm{mCi})$ of metastable Technetium 99-labeled Hydroxy Methylene Diphosphonate (HMDP-99mTc) were performed with a Siemens 
gamma camera model Symbia T6 2010. The planar bone scintigraphy showed hyperfixation of variable intensity including a very intense hyperfixation with regard to the facial mass, left maxillary and skull base, a moderate and heterogeneous hyperfixation of the two humeral diaphyses more marked on the right and a moderately intense hyperfixation of the left coxo-femoral, femur and tibial diaphysis. This aspect was suggestive of polyostotic fibrous dysplasia, thus confirming the diagnosis of McCune Albright syndrome in this infant (Figure 1).

\section{Discussion}

McCune Albright syndrome is a rare genetic disorder, due to a somatic mutation in exon 8 of the GNAS gene causing a substitution of arginine at position 201 by a histidine or cystidine, responsible for constitutive activation of adenylate cyclase resulting in an increase in intracellular cAMP, leading to increased production of melanin, oestradiol, testosterone, thyroxine, growth hormone or cortisol depending on the affected tissue $[3,4]$. McCune Albright syndrome is a rare disease and reliable data of prevalence are not available (the estimated prevalence ranges between $1 / 100,000$ and $1 / 1,000,000)$. In contrast, the skeletal aspect of the disease, fibrous dysplasia, especially monostotic disease, is not rare. Fibrous dysplasia has been reported to account for up to $7 \%$ of all benign bone tumors. However, there are no specific recommendations regarding the molecular diagnosis of McCune Albright syndrome. Lombroso, et al. In a study of 113 patients, only $8 \%$ of patients had a single sign of the disease [5]. The extent of this syndrome depends on the proliferation, migration and survival of cells in which the mutation occurred spontaneous-

\section{SCINTIGRAPHIE OSSEUSE AU HDP - TC99M}

$\mathrm{D}$

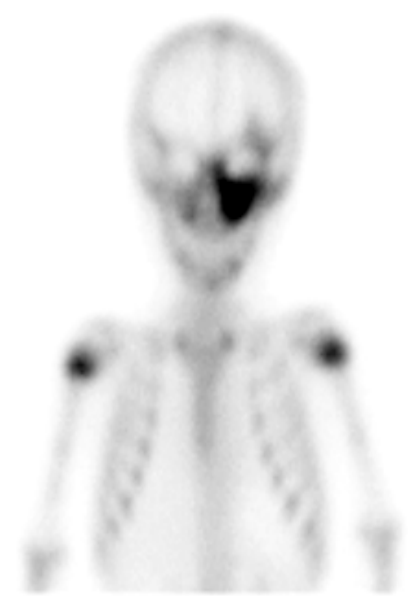

1/CRANE +THORAX ANT

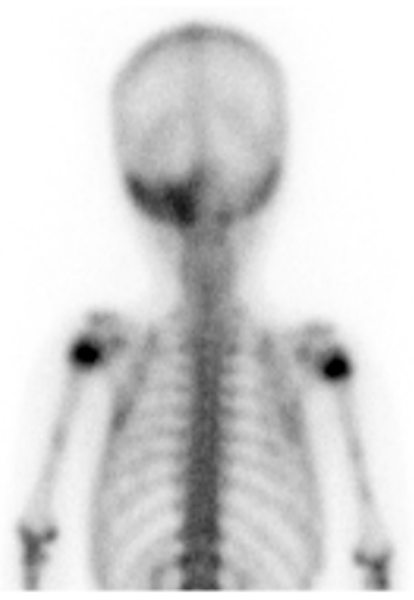

1./CRANE +THORAX POST

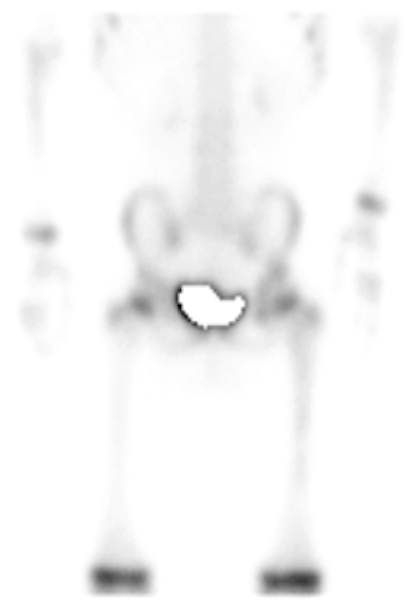

2/BASSIN ANT

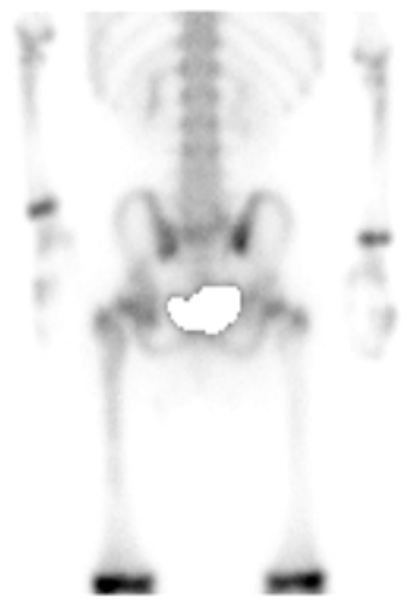

2./BASSIN POST
3/MBR INF ANT
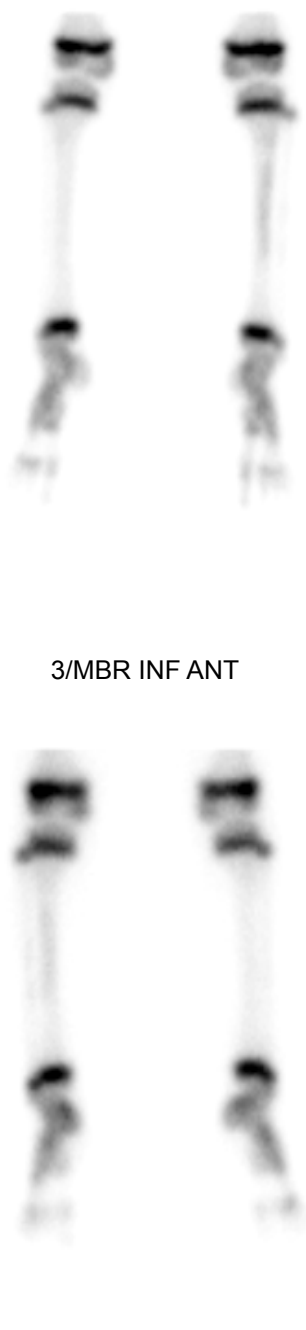

3./MBR INF POST

Figure 1: Static images highlighting a very intense hyperfixation with regard to the facial mass, the left maxillary and the base of the skull, a moderate and heterogeneous hyperfixation with regard to the two humeral diaphyses more marked on the right; moderately intense hyperfixation of the left coxofemoral, femur, and tibial diaphysis. 
Table 1: Comparison of clinical presentation according to different studies.

\begin{tabular}{|l|l|l|l|}
\hline Authors & « café au lait » skin pigmentation & Endocrinopathy & Fibrous dysplasia \\
\hline Jung, et al. [6] Strasbourg, France & Yes & No & No \\
\hline Ezzine, et al. [4] Sousse, Tunisie & Yes & Yes & Yes \\
\hline Boudriga, et al. [5] Sousse, Tunisia & Yes & Yes & Yes \\
\hline Our study, Fez Morocco & No & Yes & Yes \\
\hline
\end{tabular}

ly during embryonic development. Its age of revelation is variable, but it occurs mostly in childhood and most often affects female subjects. Classically, it associates a triad with a polyostotic fibrous dysplasia (DFP); "café au lait" skin pigmentation and hyper functioning endocrinopathy such as hyperthyroidism, ACTH-dependent Cushing's syndrome, acromegaly, precocious puberty, hyperprolactinemia, type 1 diabetes. Hepatobiliary disorders and Pancreatic diseases have also been described in patients with McCune Albright syndrome by Gaujoux, et al. Thus, the number of tissues reached, and the severity of the disease depend on the time of development at which the genetic mutation occurs and the importance of mosaicism [6-8]. As its result, the classic triad of McCune Albright syndrome with the presence of "caféau-lait" skin pigmentation would not be a dogma, as our study shows (Table 1 ).

Fibrous dysplasia in McCune Albright's syndrome is characterized by a localized proliferation of fibrous tissue in the bone marrow and classified as a benign tumor although the risk of progression of these bone lesions as sarcoma is estimated at $4 \%$. In our study, a bone scan with HMDP-99mTc was useful for the diagnosis of fibrous dysplasia, despite the absence of cutaneous lesions as "café au lait" spots [9-12]. Bone scintigraphy greatly contributed to the diagnosis of McCune Albright syndrome in a polyostotic presentation and established the initial lesion pattern of bone involvement of the disease.

\section{Conclusion}

This observation shows the importance of HMDP-99mTc bone scintigraphy in the early diagnosis of McCune Albright syndrome, which allows to highlight polyostotic fibrous dysplasia and to establish a lesion mapping of the affected bone sites, thus allowing easy a better management and subsequent monitoring.

\section{Declaration of Links of Interest}

The authors did not specify their possible links of interest.

\section{References}

1. Boyce AM, Florenzano P, de Castro LF (2015) Fibrous Dysplasia/McCune-Albright Syndrome. US National Library of Medicine.

2. (2012) Protocole national de diagnostic et de soins pour les maladies rares. Dysplasie fibreuse des os et syndrome de McCune Albright.

3. Narumi S, Matsuo K, Ishii T, Tanahashi Y, Hasegawa T (2013) Quantitative and sensitive detection of GNAS mutations causing mccune-albright syndrome with next generation sequencing. PLoS One 8: e60525.

4. Ezzine A, Regaieg $H$, Sfar R, Nouira M, Ben Fredj M, et al. (2015) Syndrome de McCune Albright: Un squelette pas comme les autres. Présentation affichées/Médecine nucléaire. CHU Sahloul. Sousse Tunisie.

5. Boudriga $H$, Ben Fredj M, Ezzine A, Mensi S, Ajmi S, et al. (2017) Scintigraphie osseuse au 99m TC-HMDP et dysplasie fibreuse polyostotique dans le cadre du syndrome de McCune -Albright : A propos d'un cas. Annales d'Endocrinologie 78: 377 .

6. Jung AJ, Soskin S, Paris F, Lipsker D (2015) Syndrome de McCune Albright révélé par des taches café-au-lait blaschko-linéaires du dos. Cas clinique. Elsevier Masson.

7. McCune DJ (1936) Osteitis fibrosa cystic: the case of nineyear-old girl who also exhibits precocious puberty, multiple pigmentation of skin and hyperthyroidism. Am J Dis Child 52: $743-744$

8. Agopiantz M, Journeau P, Lebon-Labich B, Sorlin A, Cuny T, et al. (2016) McCune Albright syndrome, natural history and multidisciplinary management in a cohort of 14 pediatric cases. Ann Endocrinol (Paris) 77: 7-13.

9. Volkl TM, Dorr HG (2006) McCune Albright syndrome: clinical picture and natural history in children and adolescents. J Pediatr Endocrinol Metab 2: 551-559.

10. Jia-woei Hou (2018) McCune Albright syndrome: Diagnosis and clinical course in eleven patients. Pediatrics and Neonatology 59: 418-420.

11. Yamamato $T$ (2006) Clinical approach to clarifying the mechanism of abnormal bone metabolism in McCune Albright syndrome. J Bone Miner Metab 24: 7-10.

12. Bousson V, Rey-Jouvin C, Laredo JD, Le Merrer M, Martin-Duverneuil N, et al. (2014) Fibrous dysplasia and McCune Albright syndrome: imaging for positive and differential diagnose prognosis and follow-up. Eur J Radiol 83: 1828-1842. 